\title{
EFEK HEMOSTATIS EKSTRAK METANOL DAUN SISIK NAGA (Drymoglossum Piloselloides Presl.) PADA TIKUS JANTAN (Rattus norvegicus L.)
}

\author{
Ika Rahayu, Hadi Kuncoro, Arsyik Ibrahim \\ Laboratorium Penelitian dan Pengembangan FARMAKA TROPIS, Fakultas Farmasi, Universitas \\ Mulawarman, Samarinda, Kalimantan Timur \\ email: ika.rahayu27@yahoo.com
}

\begin{abstract}
The research is The Hemostatic Effect of Sisik Naga Leaves (Drymoglossum Piloselloides Presl.) Metanol Extract of Rat (Rattus norvegicus L.) has been done. This reseach's purposes to determine the hemostatic effect, optimum dose and optimum measured time of Sisik Naga Leaves extract with bleeding time as its parameter used tail bleeding. Dose of Sisik Naga extract are $12.5 \mathrm{mg} / \mathrm{kgBW}, 25 \mathrm{mg} / \mathrm{kgBW}$, and $50 \mathrm{mg} / \mathrm{kgBW}$ and $\mathrm{NaCMC}$ has been used as negative control, they were given twice a day in one day treatment. Tail bleeding by cutting the rat's tail has been done on $12^{\text {th }}, 24^{\text {th }}$, and $36^{\text {th }}$ hour after the treatment. The result data was analyzed with two way Analysis of Varian (Anava) and followed BNJD test. The test results showed that bleeding time of negative control NaCMC is 143.15 seconds and bleeding time of Sisik Naga leaves extract with dose $12.5 \mathrm{mg} / \mathrm{kgBW}$ on $12^{\text {th }}$ hours 82.62 second, $24^{\text {th }}$ hours 60.27 second, $36^{\text {th }}$ hours 76.36 second, dose $25 \mathrm{mg} / \mathrm{kgBW}$ on $12^{\text {th }}$ hours 65.76 second, $24^{\text {th }}$ hours 39.33 second, $36^{\text {th }}$ hours 90.02 second, and dose $50 \mathrm{mg} / \mathrm{kgBW}$ on $12^{\text {th }}$ hours 53.97 second, $24^{\text {th }}$ hours 23.82 second, $36^{\text {th }}$ hours 72.85 . The best dose which optimum effect of hemostatic is $50 \mathrm{mg} / \mathrm{kgBW}$ with measured time on 24 hours after orally extract.
\end{abstract}

Keyword : hemostatic, Drymoglossum Piloselloides Presl., bleeding time

\begin{abstract}
Abstrak
Telah dilakukan penelitian efek hemostatis ekstrak metanol daun Sisik Naga (Drymoglossum Piloselloides Presl.) pada tikus jantan (Rattus norvegicus L.). Penelitian ini bertujuan untuk mengetahui efek hemostatis, dosis dan waktu pengukuran optimum ekstrak Sisik Naga dengan mengukur waktu perdarahan pada tikus menggunakan metode tail bleeding. Dosis uji ekstrak daun Sisik Naga yang digunakan adalah $12,5 \mathrm{mg} / \mathrm{kgBB}, 25 \mathrm{mg} / \mathrm{kgBB}$ dan 50 $\mathrm{mg} / \mathrm{kgBB}$ dengan kontrol negatif $\mathrm{NaCMC}$ yang diberikan per oral dua kali sehari selama satu hari. Pengukuran waktu perdarahan adalah 12 jam, 24 jam dan 36 jam setelah pemberian ekstrak. Data dianalisis dengan Anava dua arah yang dilanjutkan dengan uji lanjutan BNJD. Hasil penelitian menunjukkan bahwa rata-rata waktu perdarahan kontrol negatif NaCMC adalah 143,15 detik dan rata-rata waktu perdarahan ekstrak daun Sisik Naga pada dosis 12,5 $\mathrm{mg} / \mathrm{kgBB}$ pada 12 jam 82,62 detik, 24 jam 60,27 detik, 36 jam 76,36 detik, dosis 25 $\mathrm{mg} / \mathrm{kgBB}$ pada 12 jam 65,76 detik, 24 jam 39,33 detik, 36 jam 90,02 detik, dan dosis 50 mg/kgBB 12 jam 53,97 detik, 24 jam 23,82 detik, 36 jam 72,85 detik. Dosis yang paling efektif sebagai hemostatis adalah pada dosis $50 \mathrm{mg} / \mathrm{kgBB}$ dengan waktu pengukuran yang paling efektif yaitu 24 jam setelah pemberian ekstrak.
\end{abstract}

Kata kunci : Hemostatis, Drymoglossum Piloselloides Presl., waktu perdarahan 


\section{PENDAHULUAN}

Perdarahan pada umumnya menunjukkan ekstravasasi darah akibat robeknya pembuluh darah (Kumar, 2007). Pada saat terjadi perdarahan, secara alami tubuh akan merespon dengan mekanisme hemostatis untuk menghentikan perdarahan tersebut. Hemostatis adalah penghentian kehilangan darah dari pembuluh yang rusak. Mula-mula platelet melekat pada makromolekul di daerah subendotelium pembuluh darah yang luka dan merangsang aktivasi lokal faktorfaktor koagulasi didalam plasma, menyebabkan pembentukan bekuan fibrin akan terurai yang mendorong diikuti dengan terjadinya agregasi platelet dan membentuk sumbat hemostatik utama (Hardman, 2007). Sistem hemostatis yang berfungsi normal penting bagi kehidupan organisme, karena jika hemostasis terganggu maka luka yang kecil sekalipun dapat menyebabkan perdarahan yang membahayakan jiwa (Despopoulos dalam Astuti, 2011).

Perdarahan dapat diatasi salah satunya dengan menggunakan tumbuhan sebagai obat herbal. Tumbuhan yang digunakan sebagai obat untuk menghentikan perdarahan (hemostatis) antara lain adalah daun Sisik Naga. Sisik Naga merupakan tumbuhan epifit yang tumbuh dan banyak dijumpai pada daerah yang agak lembab. Sisik Naga hidup sebagai tumbuhan epifit dan bukan tumbuhan parasit karena mampu membuat makannya sendiri yang menumpang pada pohon inangnya seperti pohon mangga, rambutan, kelapa, kelapa sawit, dan lainnya. Secara emperis, masyarakat khususnya suku Jawa menggunakannya sebagai obat menghentikan perdarahan setelah melahirkan. Penggunaan empiris masyarakat tumbuhan Sisik Naga ini mempunyai potensi untuk dijadikan obat tradisional.

Metabolit sekunder daun Sisik Naga telah diindentifikasi oleh Santi pada tahun 2012 di laboratorium Kimia Farmasi Fakultas Farmasi Universitas Mulawarman yaitu terdapat senyawa golongan berupa alkoloid, flavonoid, fenol, steroid dan tanin.

Berdasarkan uraian tersebut penelitian ini dilakukan untuk menguji efek hemostatis ekstrak metanol daun Sisik Naga dengan parameter waktu perdarahan.

\section{METODE PENELITIAN}

\section{Bahan}

Bahan yang digunakan dalam penelitian adalah daun Sisik Naga yang diperoleh dari wilayah Samarinda Kalimantan Timur, pelarut metanol, NaCMC, dan bahan penunjang lainnya.

\section{Peralatan}

Peralatan yang digunakan dalam penelitian ini, antara lain seperangkat alat ekstraksi, stopwatch (Q\&Q HS43), gunting bedah steril, spuit dan sonde serta alat penunjang lainnya.

\section{Prosedur Pengambilan Sampel}

Dipilih daun Sisik Naga yang sehat dan segar. Bagian yang diteliti pada tanaman ini adalah seluruh bagian daunnya yang tumbuh di sepanjang akar yang merambat. Diambil dan dipisahkan daun dari sepanjang akarnya. Daun tanaman ini berwarna hijau, berbentuk bundar, bertangkai pendek, berdaging dan mengandung banyak air. 


\section{Prosedur Ekstraksi}

Daun Sisik Naga dibersihkan, dicuci, dipotong-potong kemudian dikeringkan dengan oven dengan suhu $40{ }^{\circ} \mathrm{C}$ sampai diperoleh bobot konstan. Dimaserasi dengan metanol berulang-ulang sampai cairan penyari bening. Hasil maserasi disaring kemudian dipekatkan dan sisa metanol diuapkan hingga diperoleh ekstrak kental.

\section{Prosedur Pengujian}

Tikus dibagi secara acak menjadi 4 kelompok perlakuan yang masing-masing kelompok terdiri dari 3 ekor tikus. Kelompok 1 diberi Na CMC 0,1\% sebagai kontrol negatif, kelompok 2 diberi ekstrak Sisik Naga dosis 12,5 $\mathrm{mg} / \mathrm{kgBB}$, kelompok 3 diberi ekstrak Sisik Naga dosis $25 \mathrm{mg} / \mathrm{kgBB}$, kelompok 4 diberi ekstrak Sisik Naga dosis $50 \mathrm{mg} / \mathrm{kgBB}$, diberikan secara peroral sesuai perlakuan kelompok dua kali sehari (setiap 12 jam) selama sehari. Uji waktu perdarahan dilakukan 12 jam, 24 jam dan 36 jam setelah pemberian terakhir. Tikus dimasukkan ke dalam holder. Ujung ekor tikus dibersihkan dengan alkohol 70\% lalu ekor tikus dipotong dengan jarak $2 \mathrm{~cm}$ dari ujung ekor dengan gunting bedah steril. Darah yang menetes diserap dengan kertas penyerap (tisu). Waktu perdarahan diukur mulai dari darah keluar sampai darah berhenti dalam satuan detik menggunakan stopwatch.

\section{HASIL DAN PEMBAHASAN}

Hasil penelitian menunjukkan bahwa ekstrak daun Sisik Naga mempunyai aktivitas menghentikan perdarahan (hemostatis) yang dibuktikan dengan kemampuan ekstrak daun Sisik Naga yang dapat mempersingkat waktu perdarahan dibandingkan dengan kontrol negatif yaitu NaCMC yang disajikan dalam Tabel 1 .

Tabel 1. Hasil Pengukuran Waktu Perdarahan

\begin{tabular}{|c|c|c|c|c|}
\hline \multirow{3}{*}{ WaktuPengukuran } & \multicolumn{4}{|c|}{ Waktu Perdarahan (detik) } \\
\hline & \multicolumn{3}{|c|}{ Dosis Uji } & \multirow{2}{*}{$\begin{array}{l}\text { Kontro } \\
\text { Negatif }\end{array}$} \\
\hline & $12,5 \mathrm{mg} / \mathrm{kgBB}$ & $25 \mathrm{mg} / \mathrm{kgBB}$ & $50 \mathrm{mg} / \mathrm{kgBB}$ & \\
\hline 12 jam & 82,62 & 65,76 & 53,97 & 143,15 \\
\hline 24 jam & 60,27 & 39,33 & 23,82 & 143,15 \\
\hline 36 jam & 76,36 & 90,02 & 72,85 & 143,15 \\
\hline
\end{tabular}

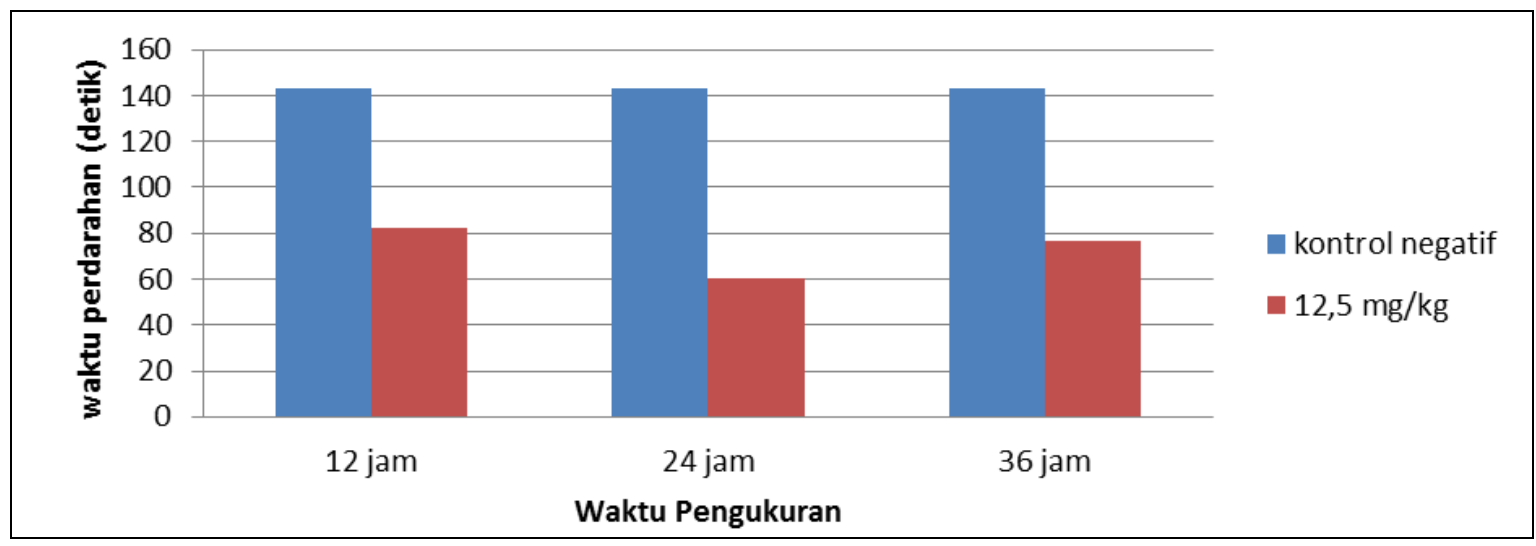

Gambar 1. Grafik Perbandingan Waktu Perdarahan antara Ekstrak Daun Sisik Naga Dosis 12,5 mg/kg dengan Kontrol Negatif 

(Rattus norvegicus L.)

Pada Tabel 1, waktu perdarahan pada tikus putih dengan pemberian ekstrak daun Sisik Naga pada dosis $12,5 \mathrm{mg} / \mathrm{kg}$ dibandingkan dengan kontrol negatif NaCMC dapat diperlihatkan oleh Gambar 1.

Hasil penelitian menunjukkan bahwa ekstrak daun Sisik Naga dengan dosis 12,5 $\mathrm{mg} / \mathrm{kg}$ dapat memberikan efek hemostatis dibandingkan konrol negatif NaCMC. Waktu perdarahan pada waktu pengukuran 12 jam adalah rata-rata 82,62 detik, pada waktu pengukuran 24 jam waktu perdarahan menjadi lebih cepat yaitu 60,27 detik, dan pada waktu pengukuran 36 jam waktu perdarahan menjadi 76,36 detik.

Waktu perdarahan pada tikus putih dengan pemberian ekstrak daun Sisik Naga pada dosis $25 \mathrm{mg} / \mathrm{kg}$ dibandingkan dengan kontrol negatif $\mathrm{NaCMC}$ diperlihatkan oleh Gambar 2.

Hasil penelitian menunjukkan bahwa ekstrak daun Sisik Naga dengan dosis 25 $\mathrm{mg} / \mathrm{kg}$ dapat memberikan efek hemostatis dibandingkan konrol negatif NaCMC. Waktu perdarahan pada waktu pengukuran 12 jam adalah rata-rata 65,76 detik, pada waktu pengukuran 24 jam waktu perdarahan menjadi lebih cepat yaitu 39,33 detik, dan pada waktu pengukuran 36 jam waktu perdarahan menjadi 90,02 detik.

Hasil pengukuran waktu perdarahan pada tikus putih dengan pemberian ekstrak daun Sisik Naga pada dosis $50 \mathrm{mg} / \mathrm{kg}$ dibandingkan dengan kontrol negatif $\mathrm{NaCMC}$ diperlihatkan oleh Gambar 3.

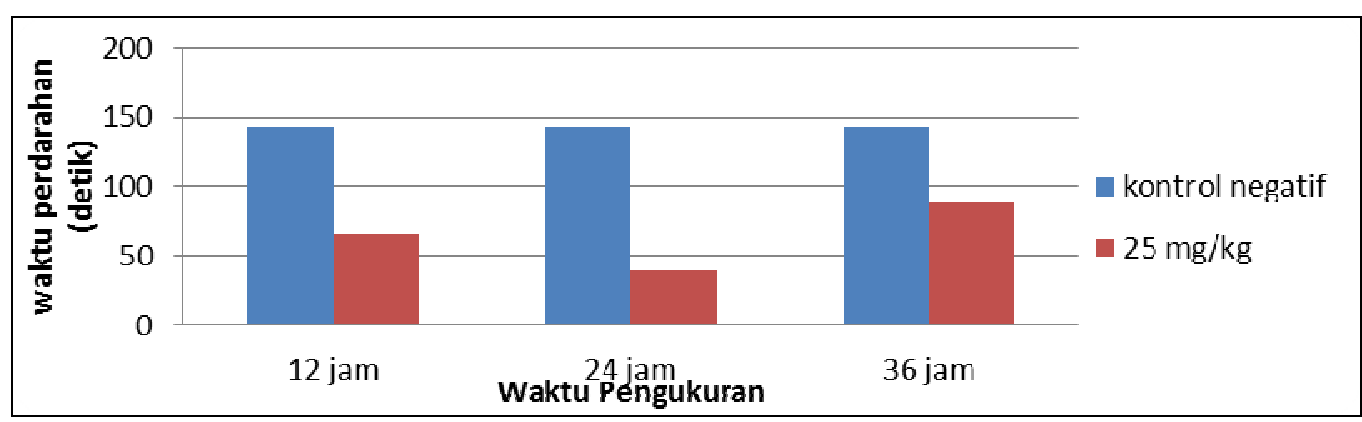

Gambar 2. Grafik Perbandingan Waktu Perdarahan antara Ekstrak Daun Sisik Naga Dosis 25 mg/kg dengan Kontrol Negatif

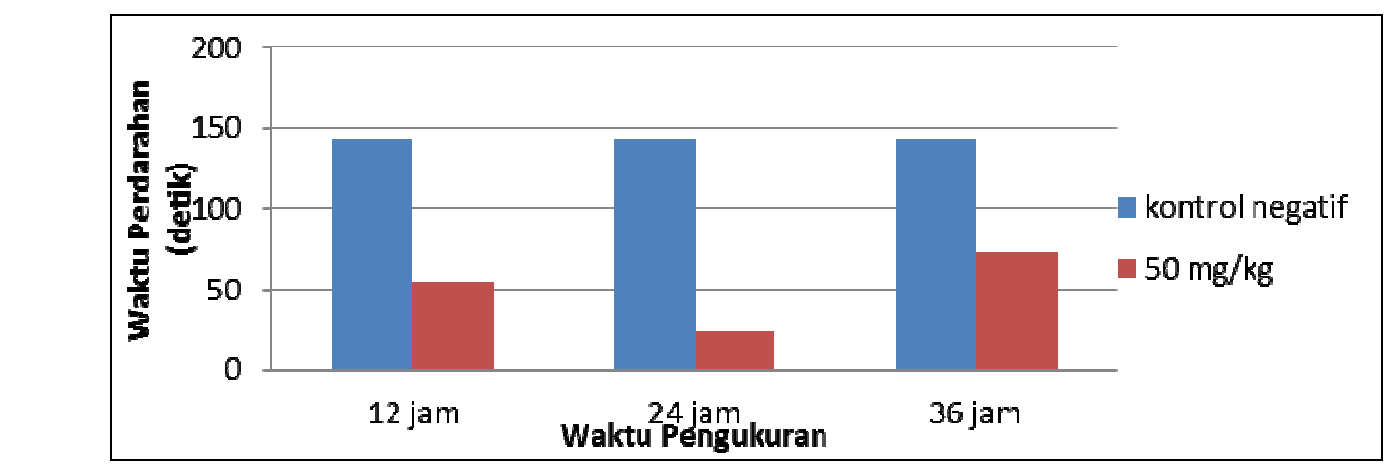

Gambar 3. Grafik Perbandingan Waktu Perdarahan antara Ekstrak Daun Sisik Naga Dosis 50 mg/kg dengan Kontrol Negatif 
Efek Hemostatis Ekstrak Metanol Daun Sisik Naga (Drymoglossum piloselloides Presl.) Pada Tikus Jantan (Rattus norvegicus L.)

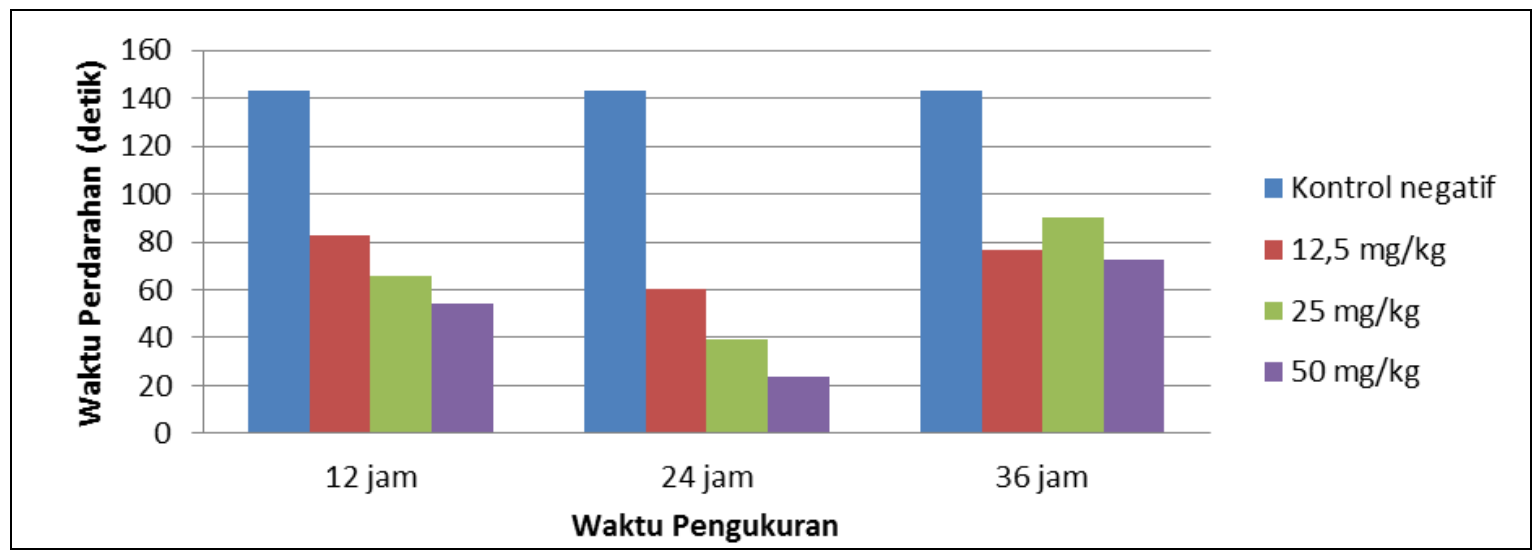

Gambar 4. Grafik Perbandingan Waktu Perdarahan Ekstrak Daun Sisik Naga dengan Kontrol Negatif

Gambar 3 tersebut menunjukkan bahwa ekstrak daun Sisik Naga dengan dosis 50 $\mathrm{mg} / \mathrm{kg}$ dapat memberikan efek hemostatis dibandingkan konrol negatif NaCMC. Waktu perdarahan pada waktu pengukuran 12 jam adalah rata-rata 53,97 detik, pada waktu pengukuran 24 jam waktu perdarahan menjadi lebih cepat yaitu 23,82 detik, dan pada waktu pengukuran 36 jam waktu perdarahan menjadi 72,85 detik.

Pengukuran waktu perdarahan ekstrak daun Sisik Naga dengan dosis 12,5 $\mathrm{mg} / \mathrm{kgBB}, 25 \mathrm{mg} / \mathrm{kgBB}$ dan $50 \mathrm{mg} / \mathrm{kgBB}$ terhadap kontrol negatif dapat dilihat dari Gambar 4.

Gambar 4. menunjukkan bahwa semua variasi dosis ekstrak daun Sisik Naga mempunyai efek hemostatis dengan mempersingkat waktu perdarahan. Data tersebut menunjukkan bahwa waktu perdarahan yang singkat pada semua dosis ekstrak daun Sisik Naga terjadi pada waktu pengukuran 24 jam. Waktu perdarahan pada waktu pengukuran 12 jam dan 36 jam lebih besar dibanding pada waktu pengukuran 24 jam. Hal ini diduga ekstrak daun Sisik Naga pada waktu 12 jam setelah pemberian belum mencapai kadar yang mencukupi untuk memberikan efek yang maksimal, ekstrak memberikan efek maksimal untuk mempercepat waktu perdarahan pada waktu pengukuran 24 jam, sedangkan meningkatnya waktu perdarahan pada waktu pengukuran 36 jam menunjukkan bahwa kerja ekstrak mulai berkurang. Artinya, waktu kerja ekstrak daun Sisik Naga dalam memberikan efek yang maksimal terjadi pada rentang sesudah 12 jam dan sebelum 36 jam pemberian ekstrak.

Hasil analisis dengan menggunakan Anava dua arah antara waktu perdarahan dengan variasi dosis diperoleh $F_{\text {hitung }}(107,17)>$ $\mathrm{F}_{\text {tabel }} 5 \%(3,01)$ dan $\mathrm{F}_{\text {tabel }} 1 \%(4,72)$ yang artinya terdapat pengaruh yang sangat signifikan pemberian variasi dosis ekstrak daun Sisik Naga terhadap waktu perdarahan. Hal ini menandakan bahwa perbedaan dosis ekstrak daun Sisik Naga juga akan mengakibatkan perbedaan waktu perdarahan. Untuk analisis waktu pengukuran terhadap waktu perdarahan diperoleh $\mathrm{F}_{\text {hitung }}(18,64)>\mathrm{F}_{\text {tabel }} 5 \%(3,40)$ dan $F_{\text {tabel }} 1 \%(5,61)$ yang artinya terdapat pengaruh yang sangat signifikan waktu pengukuran terhadap waktu perdarahan. Hal ini menandakan bahwa perbedaan waktu pengukuran akan mengakibatkan perbedaan waktu perdarahan. Untuk interaksi antara dosis terhadap waktu pengukuran diperoleh $\mathrm{F}_{\text {hitung }}(3,73)>\mathrm{F}_{\text {tabel }}$ $5 \%(2,51)$ dan $\mathrm{F}_{\text {tabel }} 1 \%(3,67)$ yang artinya terdapat interaksi yang sangat signifikan 
antara dosis dan waktu pengukuran terhadap waktu perdarahan. Hal ini menandakan bahwa perbedaan dosis dan perbedaan waktu pengukuran akan mengakibatkan perbedaan waktu perdarahan yang sangat signifikan. Artinya, efek hemostatis ekstrak daun Sisik Naga bergantung pada dosis dan waktu pengukuran.

Data kemudian dianalisis dengan uji lanjutan yang sesuai dengan koefisien keseragaman (KK). Perhitungan KK untuk pengaruh dosis adalah $148 \%$ dan KK untuk pengaruh waktu adalah $62 \%$, dan uji lanjutan yang sesuai adalah uji BNJD (Beda Nyata Jujur Duncan). Uji lanjutan ini bertujuan untuk mengetahui dosis dan waktu pengukuran terbaik terhadap waktu perdarahan sebagai hemostatis. Hasil uji BNJD waktu perdarahan terhadap dosis diketahui bahwa ekstrak daun Sisik Naga pada dosis $12,5 \mathrm{mg} / \mathrm{kg}, 25 \mathrm{mg} / \mathrm{kg}$, dan $50 \mathrm{mg} / \mathrm{kg}$ berbeda sangat signifikan dengan kontrol negatif. Dosis $12,5 \mathrm{mg} / \mathrm{kg}$ berbeda signifikan dengan dosis $25 \mathrm{mg} / \mathrm{kg}$ dan berbeda sangat signifikan dengan dosis $50 \mathrm{mg} / \mathrm{kg}$. Dan dosis $50 \mathrm{mg} / \mathrm{kg}$ berbeda sangat signifikan dengan semua dosis. Dari data uji BNJD dapat disimpulkan bahwa dosis terbaik ekstrak daun Sisik Naga yang memberikan efek hemostatis adalah pada dosis $50 \mathrm{mg} / \mathrm{kgBB}$ karena memberikan nilai signifikasi yang paling besar.

Hasil uji lanjutan BNJD waktu perdarahan terhadap waktu pengukuran menunjukkan bahwa terdapat perbedaan yang signifikan antara waktu pengukuran 24 jam dengan 36 jam, artinya dengan dosis yang sama pada waktu pengukuran 24 jam dan 36 jam akan menghasilkan waktu perdarahan yang berbeda secara signifikan. Dari hasil uji BNJD ini dapat disimpulkan bahwa waktu pengukuran terbaik untuk menghasilkan efek hemostatis adalah pada waktu pengukuran 24 jam karena memberikan nilai yang signifikan dengan waktu pengukuran lainnya.

\section{KESIMPULAN}

Ekstrak metanol daun Sisik Naga mempunyai efek hemostatis. Dosis optimum ekstrak metanol daun Sisik Naga sebagai hemostatis yaitu pada 50 $\mathrm{mg} / \mathrm{kgBB}$ pada waktu pengukuran optimum yaitu 24 jam setelah pemberian ekstrak.

\section{SARAN}

1. Perlu dilakukan pengembangan penelitian efek hemostatis terhadap fraksi-fraksi daun Sisik Naga.

2. Perlu dilakukan pengujian dosis toksik ekstrak daun Sisik Naga pada tikus putih.

3. Perlu dilakukan penelitian terhadap bagian lain dari tumbuhan seperti bagian akarnya.

\section{UCAPAN TERIMA KASIH}

Penulis menyampaikan ucapan terima kasih kepada Ketua UP. Fakultas Farmasi Universitas Mulawarman, dosen pembahas, para laboran dan sahabatsahabat yang telah memberikan saran, bantuan, waktu, dan motivasi sehingga dapat menyelesaikan artikel ilmiah ini.

\section{DAFTAR PUSTAKA}

1. Astuti, K.W. 2011. Kombinasi Asetosal dan Ekstrak Buah Mengkudu (Morinda citrifolia L.) Dapat Memperpanjang Waktu Perdarahan dan Koagulasi Pada Mencit. Program Pascasarjana Universitas Udayana : Bali.

2. Hardman, J.G.; \& Limbrid, L.E. 2007. Goodman \& Gilman Dasar Farmakologi Terapi Volume 2. Penerbit Buku Kedokteran EGC : Jakarta. 
Efek Hemostatis Ekstrak Metanol Daun Sisik Naga (Drymoglossum piloselloides Presl.) Pada Tikus Jantan (Rattus norvegicus L.)

3. Kumar, V.; Ramzi S.C.; \& Stanley L.R. 2007. Buku Ajar Patologi Volume 1 Edisi 7. Penerbit Buku Kedokteran EGC: Jakarta.

4. Santi. 2012. Kandungan Metabolit Sekunder dan Bioaktifitas terhadap Artemia Salina Leach
Ekstrak Daun Sisik Naga (Drymoglossum piloselloides). Skripsi tidak diterbitkan. Fakultas Farmasi Universitas Mulawarman: Samarinda. 